\title{
Differential Expression of Two Different EeSTM Genes of Leafy Spurge (Euphorbia esula) and Root-directed Expression from EeSTM Promoter in Leafy Spurge and Arabidopsis
}

Vijaya K. Varanasi ${ }^{1}$, Wun S. Chao ${ }^{1,2}$, James V. Anderson ${ }^{1,2}$ and David P. Horvath ${ }^{1,2 *}$

${ }^{1}$ Department of Plant Sciences, North Dakota State University, Fargo, ND 58102, USA

${ }^{2}$ United States Department of Agriculture, Agricultural Research Service, Biosciences Research Laboratory, P.O. Box 5674, State University Station, Fargo, ND 581055674, USA

\begin{abstract}
SHOOTMERISTEMLESS (STM) encodes a member of the class I KNOX homeodomain protein family that is required for meristem development and maintenance. Leafy spurge is a model perennial weed that produces adventitious meristems on its roots and hypocotyl. These buds are capable of displaying para-, endo- and ecodormancy. We have cloned two different full length cDNAs of STM (EeSTM1 and EeSTM4) from leafy spurge that displays different tissue specific expression patterns. EeSTM1 gene appears to be expressed only in young root and hypocotyl tissue. EeSTM4 is co-expressed with EeSTM1, but it is also expressed highly in the shoot apical meristem and in mature roots. An EeSTM promoter was able to drive GUS expression in the roots, hypocotyl, and shoot apical meristem of Arabidopsis, whereas the AtSTM promoter only produced GUS expression in the shoot apical meristem. Expression analysis indicates that EeSTM expression is detectable in dormant adventitious buds but is up-regulated within three days following defoliation, a treatment that initiates bud regrowth. Seasonal changes in expression of EeSTM correlated to dormancy status in underground leafy spurge buds were observed.
\end{abstract}

Keywords: STM; Leafy spurge; Promoter; Gene Expression; GUS; Bud Dormancy; Arabidopsis

\section{Introduction}

Many plants propagate through the development and regulated growth of adventitious shoot buds. Additionally, many plants maintain a pool of viable but dormant shoot buds as a means to survive periods of growth inhibiting environmental conditions. In the perennial weed leafy spurge, such buds initiate and develop on the underground roots and/or crown region and are essentially fully formed shoot meristems. Recent studies on model organisms such as Arabidopsis (Arabidopsis thaliana Hyne) have provided a greater understanding of the genes required for proper shoot meristem initiation and development. One of the genes required for shoot development is SHOOTMERSITEMLESS (STM). STM, recognized as a developmentally important gene, was first cloned from maize [1] and then later from cauliflower (Brassica oleracea var. botrytis) and Arabidopsis [2]. STM is a member of the Class I KNOX homeobox gene family. KNOX encoded transcription factors are important in regulating meristem development and maintenance [3-5]. STM in particular is required for maintaining a supply of nondifferentiated cells in the central zone of the shoot apical meristem (SAM).

STM is primarily expressed in the central zone of the SAM in Arabidopsis. STM also has a very important role in maintaining meristematic identity in cells of the peripheral zone that are not recruited to form organ primordia. ROUGH SHEATH2 (ZmRS2) in maize and ASYMMETRIC LEAVES1 (AS1) negatively regulate KNOX (KNOTTED1-like homeobox) genes such as STM in Arabidopsis [68]. RS2 and AS1encode MYB-domain proteins that down-regulate KNOX genes in developing leaves. ASYMMETRIC LEAVES2 (AS2), a LATERAL ORGAN BOUNDARIES (LOB) protein, along with AS1 repress KNOX gene expression to promote leaf differentiation [9]. CUPSHAPED COTYLEDON (CUC) initially induces AtSTM expression in the developing SAM [10]. There is evidence of both chromatin modification and transcription factor binding sites playing a role in regulation of STM in Arabidopsis and other species [11,12].

STM has been extensively studied in annual plant species such as Arabidopsis and likely orthologues have been identified in many plant species. However, very little is known about how STM is expressed in perennials that produce adventitious buds capable of various states of dormancy. It is unknown if STM is expressed in dormant buds, or if it is differentially regulated between growth and dormancy transitions. We have chosen to study STM expression in leafy spurge (Euphorbia esula L.). Leafy spurge is an herbaceous perennial weed, native to the central Europe, but which has become invasive in the Northern Great Plains of the US and Canada [13]. Genetically, leafy spurge is an autoallo hexaploid [14].

Leafy spurge is a model perennial that is ideal for studying bud dormancy [15]. Leafy spurge produces large numbers of easily identifiable adventitious buds along the lateral roots (often referred to in the literature as root buds) and on the underground stem (referred to as crown buds) [16]. Leafy spurge root and crown buds display all three types of dormancy (para-, endo- and ecodormancy) $[17,18]$. After formation in early summer, root and crown buds enter a state of paradormancy. This paradormant state is maintained throughout the growing season by auxin and sugar signals produced in the growing

*Corresponding author: David Horvath, Ph.D, United States Department of Agriculture, Agricultural Research Service, Biosciences Research Laboratory, P.O. Box 5674, State University Station, Fargo, North Dakota 58105-5674, USA,Tel: (701) 239-1255; Fax: (701) 239-1252, E-mail: david.horvath@ars.usda.gov

Received May 05, 2012; Accepted June 08, 2012; Published June 11, 2012

Citation: Varanasi VK, Chao WS, Anderson JV, Horvath DP (2012) Differentia Expression of Two Different EeSTM Genes of Leafy Spurge (Euphorbia esula) and Root-directed Expression from EeSTM Promoter in Leafy Spurge and Arabidopsis. Agrotechnol 1:102. doi:10.4172/2168-9881.1000102

Copyright: (c) 2012 Varanasi VK, et al. This is an open-access article distributed under the terms of the Creative Commons Attribution License, which permits unrestricted use, distribution, and reproduction in any medium, provided the original author and source are credited. 
Citation: Varanasi VK, Chao WS, Anderson JV, Horvath DP (2012) Differential Expression of Two Different EeSTM Genes of Leafy Spurge (Euphorbia esula) and Root-directed Expression from EeSTM Promoter in Leafy Spurge and Arabidopsis. Agrotechnol 1:102. doi:10.4172/21689881.1000102

Page 2 of 6

shoot $[19,20]$. Root and crown bud growth is reinitiated by separation of buds from the growing shoot. In the fall, root and crown buds of leafy spurge enter an endodormant state and will not grow even if plants are returned to growth-conducive conditions [18,20]. Prolonged periods of cold temperatures release the endodormant state [18]. The buds remain in an ecodormant state and will not develop into growing shoots until growth-conducive conditions return in the spring [18].

We previously isolated and characterized several genomic and cDNA clones of STM from the leafy spurge [21]. A comparison to other class I KNOX genes indicates that these EeSTM genes represented orthologues of KN2 from poplar and likely were related to ARBORKNOX1 of poplar and STM of Arabidopsis. 5' Race indicated that the transcription initiation site is close to the start of translation and is conserved between Arabidopsis and leafy spurge. Putative cis-acting elements were identified in an EeSTM promoter, including several long elements that were conserved between leafy spurge and poplar that were independently identified as part of a larger conserved region in other species [12]. Another identified putative cis-acting element resembled a tuber-specific sucrose-responsive element which was hypothesized to play a role in the expression of EeSTM in root tissue [21].

We report here the differential expression of EeSTM during various dormancy transitions, and tissue specific expression of two different EeSTM genes (EeSTM1 and EeSTM4). Additionally, reporter constructs indicate that EeSTM can drive tissue specific expression of a reporter gene in a heterologous system (Arabidopsis). We also test the activity of the tuber-specific sucrose-responsive element in driving STM expression outside the SAM in Arabidopsis. The results should prove beneficial in identifying molecular targets for regulating the development and growth of underground adventitious buds in leafy spurge and could result in better control strategies for leafy spurge and other perennial weeds with similar growth habits.

\section{Materials and Methods}

\section{Plant material}

Plants of Euphorbia esula used for the experiments were grown in cones ( 5 by $20 \mathrm{~cm}$ ) with Sunshine mix (SUN GRO Horticulture, WA, USA) under greenhouse growth conditions as single stems under $16 \mathrm{~h}$ of natural and artificial lighting. All experiments were replicated at least twice for confirmation of results.

In order to study differential expression of EeSTM after paradormancy release, leafy spurge plants growing in the green house were defoliated by excising the aerial portions at the soil surface. Adventitious buds from 21-28 plants were then harvested, pooled, and stored in liquid nitrogen at various times following excision $(0,2,4,8$, $16,24,48,72 \mathrm{~h}$ ). All the buds were harvested at the same time of the day to avoid artifacts caused by circadian effects. Real-Time PCR was done to quantify EeSTM expression (see below). Fold differences are shown relative to the $0 \mathrm{~h}$ time point. The experiment was repeated twice (two independent time course collections done several months apart).

To follow seasonal changes in EeSTM expression, adventitious root buds were harvested from leafy spurge from August 2001 through February 2005. Total RNA was extracted from these buds and cDNA synthesized. Semi-quantitative RT-PCR was done on seasonal cDNAs from 2001-02, 02-03 and 03-04. Serial dilutions of EeSTM containing plasmid was amplified in parallel as a concentration standard, and resulting gel was blotted and hybridized to ${ }^{32} \mathrm{P}$ labeled EeSTM probe. Label hybridizing to each band was quantified using a Packard Instant Imager. Real-Time PCR was performed on 2004-05 samples. The data obtained was converted to fold differences in expression for each year using August cDNA as the calibrator.

For tissue specificity studies, leafy spurge seeds were germinated on moist filter paper in Petri dishes. The Petri dishes containing leafy spurge seeds were kept in an incubator at $37^{\circ} \mathrm{C}$. The hypocotyl and radicle tissues were collected 8-10 d after emergence and elongation from the seed. Mature root tissue was collected from 4 month old leafy spurge plants. Adventitious buds were removed from the roots before harvest. Leafy spurge leaves were collected from middle $1 / 3$ rd of the stalk. Meristems were collected by excising the tip of the leafy spurge plant and removing most of the immature leaves from the shoot tip. All the leafy spurge tissues (hypocotyl, radicle, old root, leaf and meristem) were frozen in liquid nitrogen and stored at $-80^{\circ} \mathrm{C}$.

\section{Real-Time PCR}

Expression analysis of EeSTM was characterized by Real-Time PCR. For all analyses except the time course following paradormancy release, TaqMan chemistry was used in a 7300 Real-Time PCR system. A two-step RT-PCR assay was used for relative quantitation of EeSTM cDNA synthesized from time-course and seasonal RNA's. Total RNA was extracted from underground adventitious buds of leafy spurge at various times using the pine tree extraction method [22]. cDNA was synthesized from samples and trace amounts of ${ }^{32} \mathrm{P}$-dCTP were included to help assess the quality and quantity of the resulting cDNA via gel electrophoresis, blotting, and quantification of the incorporated label. All samples were amplified in triplicate using ATG ATT GCT TTT GGA GAC AAC A (5') and AGT CTG CAT TAT GAT GAT GAT G (3') primer sequences. The FAM dye-labeled TaqMan probe sequence used for this study was TGG AGG AGG AGG AGG AGG AG. $\mathrm{T}_{\mathrm{m}}$ for primers and probe was $60^{\circ} \mathrm{C}$ and $70^{\circ} \mathrm{C}$. Various microarray experiments suggest that a large number of endogenous genes are differentially regulated during dormancy transitions, thus we chose to use an exogenous spike control (total Human cDNA) to normalize quantification of the target cDNA. Multiplex PCR was performed in each reaction tube containing $0.02 \mu \mathrm{g}$ of total leafy spurge cDNA and $0.01 \mu \mathrm{g}$ of total human cDNA with primers and probes corresponding to EeSTM and human GAPDH. A comparative CT (Threshold cycle) method was used in which the EeSTM cDNA was normalized to an exogenous (spiked control) reference (Human GAPDH). Serial dilutions (10 fold) of the EeSTM cDNA clone were included as external quantification controls. A negative control without EeSTM CDNA and a GAPDH control were also included in this expression study. All reactions were run in triplicate. For the paradormancy release time course, equal amounts of cDNA were used in each reaction and reactions were run in triplicate. SYBR green and the endogenous ROX reference dye were used to determine relative CT values. Numerous genes with expression patterns confirmed by northern hybridization (HISTONE H3 being only one such gene shown) were run concurrently to ensure appropriate amplification and quantification of each sample.

\section{Allelic discrimination assay}

An allelic discrimination assay was conducted on cDNA synthesized from various leafy spurge tissues. All samples (hypocotyl, radicle, old root, leaf, and meristem) were amplified in triplicate using GCACTACTGGTGGTTCTTCTTCT $\left(5^{\prime}\right)$ and GCAGTGTTTGAGTTTGAGTTTGTGT (3') primer sequences. Two probes were used, one specific to EeSTM1 (VIC labeled TGATCGTCAATAATCAT) allele and the other specific to EeSTM4 allele (FAM labeled - ATCGTCAAGAATCAT). A standard 96-well reaction plate was used for loading samples and for the Pre-read, 
Citation: Varanasi VK, Chao WS, Anderson JV, Horvath DP (2012) Differential Expression of Two Different EeSTM Genes of Leafy Spurge (Euphorbia esula) and Root-directed Expression from EeSTM Promoter in Leafy Spurge and Arabidopsis. Agrotechnol 1:102. doi:10.4172/21689881.1000102

Amplification, and Post-read steps of the assay. Both negative and positive controls were included. Analysis was done using the SDS software (v 1.4.1)

\section{Transgene construction}

Primers sequences CCGCTCTAGAAGTACTCTCG $\left(5^{\prime}\right)$ and CTCTCCTCAACAAATCCTAC (3') were used to amplify 1,918 base pairs (bp) of promoter sequence (including $5^{\prime}$ UTR) from the EeSTM genomic clone (Genbank accession \#EF636204). Likewise, primers sequences ACGAATCACTGTCCTTAACC $\left(5^{\prime}\right)$ and CTTCTCTTTCTCTCACTAG (3') were used to amplify up to $1,934 \mathrm{bp}$ of the STM promoter sequence (including $5^{\prime}$ UTR) from genomic DNA of Arabidopsis. For functional analysis of the putative sucrose-responsive element - STK (STOREKEEPER) binding site, primers were developed to replace the STK binding site with a sequence containing a BamHI restriction site. Two primer sets, CCGCTCTAGAAGTACTCTCG (5'), ATGGATCCAGTGGTCTCCCG (3') and GTGGATCCCTTTGTGGCTAT (5'), CTCTCCTCAACAAATCCTAC (3') were used to amplify two fragments from the EeSTM promoter sequences immediately flanking the STK element. The PCR amplified promoter fragments were digested with $\mathrm{BamHI}$ and ligated to form a single contiguous promoter without the sucrose element. The amplified DNAs were gel purified and ligated into pBI121, replacing the cauliflower mosaic virus $35 \mathrm{~S}$ promoter (CaMV 35S). Constructs were confirmed by PCR and used to transform Arabidopsis.

\section{Transformation of Arabidopsis}

Seeds of the wild-type Arabidopsis (Columbia) were sown in green house pots and grown until they begin flowering and ready for transformation. These flowering Arabidopsis plants were transformed by Agrobacterium tumefaciens (strain GV3101) harboring the binary vector pBI 121 containing EeSTM promoter constructs using the floral dip method [23]. Putative transgenic seeds $\left(\mathrm{T}_{1}\right)$ from $7-10$ independent lines for each construct were collected and re-screened for kanamycin resistance $\left(\operatorname{Kan}^{\mathrm{r}}\right)$. Several plants each from at least three lines from each construct that produced $\operatorname{Kan}^{\mathrm{r}}$ seeds $\left(\mathrm{T}_{2}\right)$ were transplanted in potting mix and allowed to mature. Transformation of $\mathrm{T}_{2}$ plants was confirmed by PCR using a GUS primer (5' TTCATGACG ACCAAAGCCAGTAAAGT $3^{\prime}$ ) and one of the $5^{\prime}$ STM promoter primers from leafy spurge or Arabidopsis. The amplified DNA band was confirmed for each construct by sequencing. Transgenic plants were allowed to grow and produce seeds $\left(\mathrm{T}_{3}\right) \cdot 20-40 \mathrm{~T}_{3}$ seedlings each from at least three lines for each construct were GUS stained to characterize the activity of the leafy spurge and Arabidopsis STM promoters.

\section{Results}

\section{EeSTM expression following release from paradormancy}

Two full length cDNA (EF636205, EF636206) of EeSTM were obtained (EeSTM1 and EeSTM4) [21]. Since both clones were similar, the initial analysis of expression was done using a primer and probe set designed to detect both transcripts. AtSTM is required for development and maintenance of the shoot apical meristem in Arabidopsis [3]. However, it is not clear if EeSTM was expressed in dormant meristems or if growth induction had any impact on EeSTM expression. We investigated EeSTM expression in paradormant and growing buds of leafy spurge using Real-Time PCR with primers that would amplify any known EeSTM genes (Figure 1). EeSTM is initially down-regulated shortly after release of buds from paradormancy by defoliation and then within $4 \mathrm{~h}$, EeSTM expression steadily increases above initial levels for 2-3 d. Interestingly, increased EeSTM expression clearly precedes
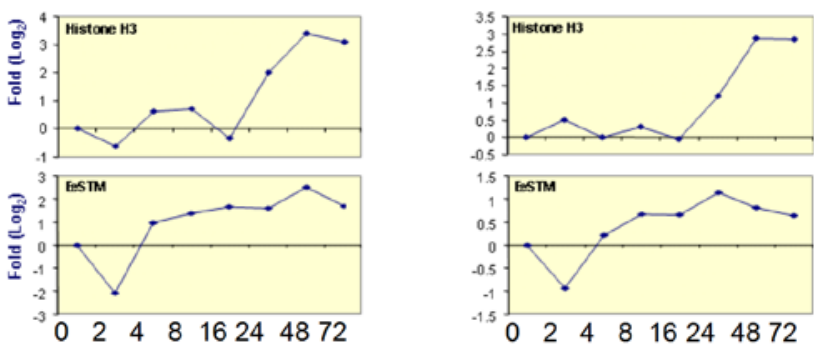

Hrs after growth induction

Figure 1: Real-Time PCR analysis of EeSTM and HISTONE H3 expression in underground buds of leafy spurge. Crown buds were collected at various times following release of buds from paradormancy. Real-Time PCR analyses from two independently isolated time course series are shown. Expression pattern was relative to non-growing crown buds (time 0 ).

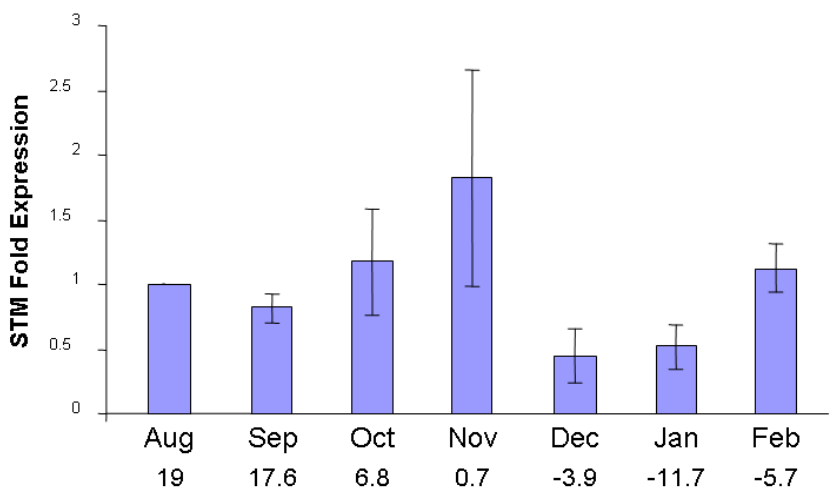

Figure 2: Seasonal expression of EeSTM. EeSTM expression was examined in crown buds collected monthly over 4 years. August cDNA was used as a calibrator for relative quantification of EeSTM. Error bars represent standard error. The average temperature during the week prior to bud harvest is noted below each sample point.

the induction of HISTONE H3 which was up-regulated only after $16 \mathrm{~h}$ following growth induction.

\section{Seasonal expression of EeSTM}

Leafy spurge buds can be maintained in a paradormant, endodormant or ecodormant state, and the transition from paradormancy to growth resulted in a change in EeSTM levels. Thus, it was of interest to determine if EeSTM expression was differentially regulated during the seasonal transition from paradormancy to endo- or ecodormancy. EeSTM expression was examined in buds collected monthly over several different years. Although there was a significant trend for EeSTM expression to drop in Dec. and Jan. and then increased in late winter, EeSTM expression fluctuated substantially between monthly samples depending on the year, particularly during Oct. and Nov. when buds were endodormant (Figure 2).

\section{Tissue specific expression of EeSTM}

The presence of possible root-specific cis-acting elements in the promoter of EeSTM, and the ability of leafy spurge to develop adventitious buds on its root system suggested the possibility that EeSTM could be expressed in root tissue. To determine which tissues EeSTM was expressed in leafy spurge, Real-Time PCR was used to analyze RNA from leaf, meristem, young hypocotyl, young root, and old root tissue (devoid of visible adventitious buds) (Figure 3). Surprisingly, these experiments indicated that maximum expression of EeSTM was 
Citation: Varanasi VK, Chao WS, Anderson JV, Horvath DP (2012) Differential Expression of Two Different EeSTM Genes of Leafy Spurge (Euphorbia esula) and Root-directed Expression from EeSTM Promoter in Leafy Spurge and Arabidopsis. Agrotechnol 1:102. doi:10.4172/21689881.1000102

Page 4 of 6

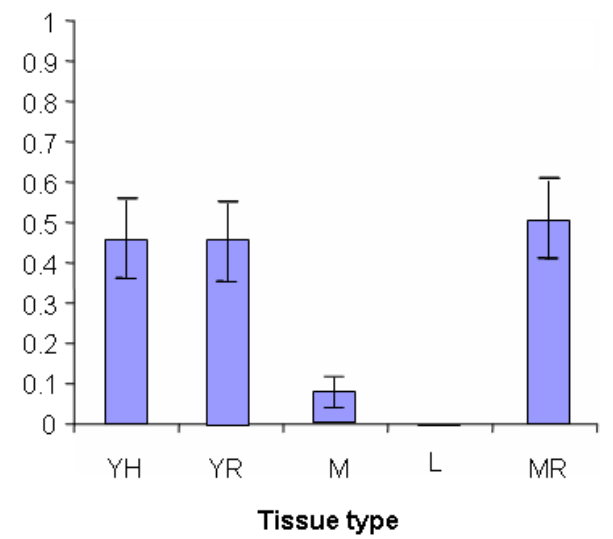

Figure 3: Relative tissue specific expression of EeSTM from three independent samples as quantified by Real-Time PCR. Error bars standard error from three different samples for each tissue. Tissues from young hypocotyl (YH), young root (YR), shoot meristem (M), leaves (L), and mature root (MR), were used for this study.

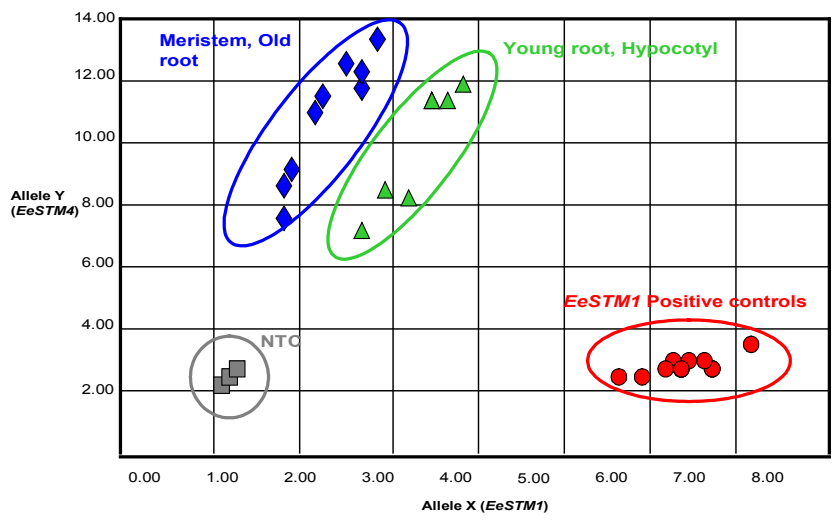

Figure 4: Real-Time Allelic Discrimination Assay of EeSTM1 and EeSTM4 alleles. Each dot represents a well in the 96-well reaction plate of Real-Time assay. Tissues containing only EeSTM4 (diamonds) are aligned more towards the upper left corner of the plot, whereas control samples containing only EeSTM1 (circles) are aligned more towards the lower right corner of the plot Tissues containing both alleles (triangles) are approximately midway between the above two groupings. Negative controls (squares) grouped in the bottom left as expected. Data were plotted by using the absolute fluorescence of each reporter dye probe.

in old roots followed by young roots, young hypocotyl, meristem, in that order, but not in the leaf tissue as would be expected for an STM orthologue. Expression of EeSTM in old and young roots and hypocotyl of leafy spurge seedlings is consistent with the ability of leafy spurge to form adventitious meristems in these tissues.

\section{Differential tissue specific expression of EeSTM1 and EeSTM4}

The differences in the coding sequences of EeSTM1 and EeSTM4 suggested they might be homeologous or paralogous genes rather than alleles of the same gene. Thus, it was possible that these genes might have different expression profiles. To test this hypothesis, an allelic discrimination assay was conducted to detect variation in expression patterns of EeSTM1 and EeSTM4 in various tissues of leafy spurge (Figure 4). EeSTM4 expression was detected in all tissues tested, however surprisingly EeSTM1 was only called as "present" in the young root and hypocotyl.

\section{Heterologous activity of the EeSTM promoter in Arabidopsis}

Screening of a leafy spurge genomic library only identified a single clone with defined promoter sequence [21]. The coding sequence from this clone was most similar, but not identical, to EeSTM4. The presence of conserved sequences in this EeSTM promoter suggested that it might be able to accurately direct expression of a reporter gene in a heterologous system such as Arabidopsis [21]. To test this hypothesis, the $2000 \mathrm{bp}$ fragment of the EeSTM genomic clone including the 5'UTR sequence was used to drive GUS expression in transgenic Arabidopsis. The results indicated that this EeSTM promoter could direct GUS expression in the SAM of Arabidopsis (Figure 5). Interestingly, GUS expression was also observed in the hypocotyl and root pericycle of the transgenic plants carrying the EeSTM:GUS construct, whereas the construct containing a similar region of the AtSTM promoter only drove GUS expression in the meristem (Figure 5). This observation is consistent with expression of EeSTM in the root and hypocotyl observed in leafy spurge, and supports the hypothesis that elements within this EeSTM promoter might be needed for development of underground adventitious shoots in leafy spurge.

\section{Root and hypocotyl expression is not dependent on STK element}

Initial characterization of the EeSTM promoter identified a putative root-specific sucrose-responsive element (STOREKEEPER binding site- STK) that was unique to leafy spurge [21]. Consequently we hypothesized that this element might be involved in regulating expression of EeSTM in root tissue. We therefore deleted this element in our reporter gene and analyzed GUS expression in transgenic Arabidopsis. The results clearly indicated that GUS was still expressed in roots and hypocotyls of transgenic Arabidopsis (Figure 5). Thus, it appeared that deletion of this element had no effect on expression from the EeSTM promoter.

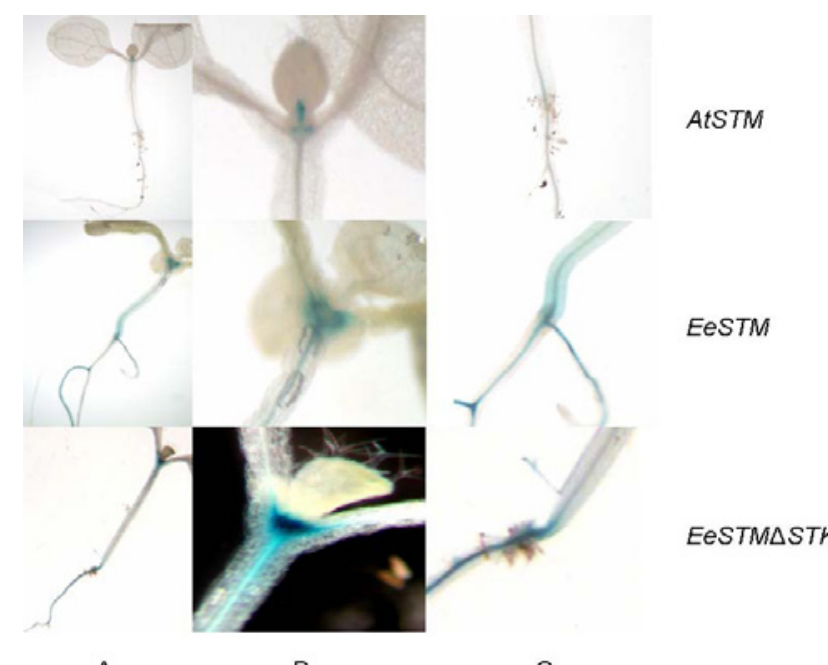

B

Figure 5: GUS expression in transgenic Arabidopsis on whole plant (A), close up of meristem region (B), or of hypoctyl-root boundry (C). Representative GUS-stained plants transformed with a construct in which the AtSTM promoter and 5'UTR are driving GUS expression (AtSTM), EeSTM promoter and 5'UTR driving GUS (EeSTM), or the EeSTM promoter and 5'UTR in which the STK binding site was replaced with a BamHI restriction site (EeSTM $\triangle S T K)$. 
Citation: Varanasi VK, Chao WS, Anderson JV, Horvath DP (2012) Differential Expression of Two Different EeSTM Genes of Leafy Spurge (Euphorbia esula) and Root-directed Expression from EeSTM Promoter in Leafy Spurge and Arabidopsis. Agrotechnol 1:102. doi:10.4172/21689881.1000102

Page 5 of 6

\section{Discussion}

\section{Characterization of the EeSTM genes}

The minor differences observed between cDNA and genomic clones of EeSTM suggest there may be several alleles of EeSTM in leafy spurge [21]. This was expected since leafy spurge is an auto-allo hexaploid [14]. Given that poplar has two STM orthologues and that poplar is in the same order as leafy spurge, there could be as many as 12 or more different copies (alleles, paralogues, and homeologues) of STM in leafy spurge. EeSTM genes form a separate clade with orthologous genes from other perennials such as poplar (Populus alba), and snapdragon (Antirrhinum majus). The separate clade also includes AtSTM from Arabidopsis but excludes KNAT1 from Arabidopsis and the STM-like genes from monocots [21]. These results suggest that our EeSTM genes represent orthologues or paralogues of AtSTM rather than a different member of the Class I KNOX gene family.

\section{Regulation of EeSTM in leafy spurge and Arabidopsis}

The observation that the EeSTM promoter can direct expression in the roots of leafy spurge and Arabidopsis indicates that some conserved element directs root specific expression. Thus, the presence of a putative $S T K$ binding site in the promoter of the EeSTM gene was intriguing. STOREKEEPER (STK) is a conserved DNA-binding protein shown to recognize the $10 \mathrm{bp}$ motif (GCTAAACAAT) in potato and regulate the expression of patatin [24] in potato tubers. It is interesting to note that this $10 \mathrm{bp}$ motif is not found in the promoter of STM gene in Arabidopsis or poplar. AtSTM is not normally expressed in the roots of Arabidopsis, and poplar plants do not normally maintain a population of preformed adventitious shoot buds on their root system, although poplar can and does form adventitious shoots from its roots following damage to the root system or other shoot inducing treatments. Leafy spurge however forms viable shoot meristems on both the lateral roots and hypocotyl as early as 8 days following germination [16]. Thus it was hypothesized that this STK binding site might be important for bud formation on underground organs of leafy spurge. However, the results of these experiments (Figure 5) suggest that the putative STK binding site is not required for EeSTM expression in roots of leafy spurge. It will be interesting to determine what other elements are required for root specific expression of EeSTM genes. There are several related spurges that only form buds on hypocotyls or that do not form underground buds at all [25]. A comparison between STM gene regulations between these related species could identify elements required for root specific expression of STM.

In Arabidopsis, it appears that AtSTM is regulated by mechanisms involving chromatin remodeling [11], however there is also evidence that Myb-type transcription factors such as AS1 and CUC also regulate STM expression $[8,10]$. Although some critical biochemical components of this chromatin remodeling are well characterized, there is insufficient understanding of the targeting and action of such proteins and protein complexes to allow specific manipulation of chromatin regulated genes. Consequently, coordinated cross-species comparisons of regulatory mechanisms could shed much needed light on such processes. Since the EeSTM promoter can accurately direct meristem specific expression in a heterologous system such as Arabidopsis, and since there appear to be both conserved and species specific elements within the EeSTM promoter, chimeric constructs can be produced with elements from leafy spurge and Arabidopsis to dissect the sequences responsible for regulating this critical developmental gene.

\section{Tissue-specific expression of EeSTM and its alleles in leafy spurge}

The Real-Time expression of EeSTM in hypocotyl, old root, young root (radicle), and meristem and not in the leaf tissue is consistent with the EeSTM promoter driven GUS expression in Arabidopsis. We detected expression of both EeSTM1 and EeSTM4 genes in the juvenile tissues (radicle and hypocotyl) but only EeSTM4 in older tissues (meristem, and old root). This suggests that EeSTM1 is responding to developmental specific signals that either turn this gene on in juvenile tissue or turn it off in older tissue. Other perennials such as poplar also have paralogous copies of STM. It would be interesting to determine if there is also tissue specific regulation of paralogous in these other species. It was also surprising to note that there was relatively higher expression of EeSTM in the root and hypocotyl tissues than in the meristem. The reason for this is unclear, and needs further investigation. However, the fact that a relatively limited number of cells in the SAM express STM in Arabidopsis and that our meristem samples contained a number of immature leaves and a small portion of the stem could account for the relatively lower concentration of STM mRNA in these samples. In situ hybridizations with EeSTM specific probes and antibodies on root and meristem sections will be needed to determine if indeed EeSTM was more highly expressed on a cell by cell basis between the various root cell types and cells in the central zone of the meristem, and to determine if the EeSTM gene expression is indicative of EeSTM protein accumulation.

\section{EeSTM expression in relation to growth induction}

There is differential regulation of other genes responsive to cell cycle in growing versus non-growing tissues (dormant buds) of leafy spurge $[19,26]$. Genes like HISTONE H3, TUBULIN, and CYCLIN D3 are upregulated in underground buds after induction of growth by defoliation [19]. The Real-Time PCR results indicate that induction of EeSTM follows a roughly similar pattern of expression observed for CYCLIN D or HISTONE H3 but that the subsequent induction of EeSTM expression occurs earlier than the rise of HISTONE H3 or CYCLIN D3 expression (Figure 1) [26]. AtSTM up-regulates the cytokinin biosynthesis gene isopentenyl transferase 7 (AtIPT7) and activates cytokinin response factor, resulting in increased synthesis of cytokinin and up-regulation of cytokinin-responsive CYCLIN-D [27]. AtSTM and CYCLIN D3 are both up-regulated in abnormal meristem mutant 1 (amp 1), indicating a link between growth and development [28]. Thus, our observations are consistent with studies that suggest AtSTM expression may impact cell division processes and CYCLIN expression. Our results also suggest that induction of developmental responsive signaling systems precede induction of growth per se. Additionally, the up-regulation of EeSTM following induction of active growth suggests that EeSTM may be needed to sustain shoot growth and development in adventitious buds following re-initiation of growth.

The initial drop in EeSTM expression is also intriguing. The leafy spurge plants could be responding to wounding stress following decapitation. Down-regulation of genes for a brief period might be one of the ways to conserve energy under stress and to readjust physiology before putting forth new shoots. Elevated levels of jasmonic acid and oxophytodienoic acid produced during wounding stress [29] have an antagonistic effect on the endogenous cytokinin levels [30]. AtSTM is positively regulated by cytokinins [28]. A decreased cytokinin level could therefore down-regulate EeSTM immediately after decapitation. 
Citation: Varanasi VK, Chao WS, Anderson JV, Horvath DP (2012) Differential Expression of Two Different EeSTM Genes of Leafy Spurge (Euphorbia esula) and Root-directed Expression from EeSTM Promoter in Leafy Spurge and Arabidopsis. Agrotechnol 1:102. doi:10.4172/21689881.1000102

Page 6 of 6

\section{Expression of EeSTM during dormancy transitions}

The relative down regulation of EeSTM in early winter as the buds transition into ecodormancy, and subsequent up-regulation as the buds move out of ecodormancy in early spring is consistent with similar expression patterns observed for various cell cycle genes such as HISTONE H3 and CYCLIN D3 [26]. Also, there was substantial variation in EeSTM expression during Oct. and Nov. when the buds are in endodormancy. This variation did not appear to correlate either with temperatures near the time of harvest or the depth of the dormant state of the plants as noted in parallel experiments (data not shown). This indicates that EeSTM expression during endodormancy may be regulated by other unknown factors.

\section{Acknowledgements}

We thank Laura Kelley for technical assistance and Cheryl Kimberlin for growing leafy spurge.

\section{References}

1. Hake S, Vollbrecht E, Freeling M (1989) Cloning Knotted, the dominant morphological mutant in maize using Ds2 as a transposon tag. EMBO J 8: 15-22.

2. Granger CL, Callos JD, Medford JI (1996) Isolation of an Arabidopsis homologue of the maize homeobox Knotted-1 gene. Plant Mol Biol 31: 373-378.

3. Barton MK, Poethig RS (1993) Formation of the shoot apical meristem in Arabidopsis thaliana: an analysis of development in the wild type and in the shoot meristemless mutant. Development 119: 823-831.

4. Long J, McConnell J, Fernandez A, Grbic V, Barton MK (1996) Developmental Genetics Of Shoot Apical MERISTEM FORMATION IN ARABIDOPSIS. Plant Physiol 111: 40002

5. Groover AT, Mansfield SD, DiFazio SP, Dupper G, Fontana JR, et al. (2006) The Populus homeobox gene ARBORKNOX1 reveals overlapping mechanisms regulating the shoot apical meristem and the vascular cambium. Plant Mol Bio 61: 917-932.

6. Schneeberger R, Tsiantis M, Freeling M, Langdale JA (1998) The rough sheath2 gene negatively regulates homeobox gene expression during maize leaf development. Development 125: 2857-2865.

7. Tsiantis M, Schneeberger R, Golz JF, Freeling M, Langdale JA (1999) The maize rough sheath2 gene and leaf development programs in monocot and dicot plants. Science 284: 154-156.

8. Byrne ME, Simorowski J, Martienssen RA (2002) ASYMMETRIC LEAVES1 reveals knox gene redundancy in Arabidopsis. Development 129: 1957-1965.

9. Xu L, Xu Y, Dong A, Sun Y, Pi L, et al. (2003) Novel as1 and as2 defects in lea adaxial-abaxial polarity reveal the requirement for ASYMMETRIC LEAVES1 and 2 and ERECTA functions in specifying leaf adaxial identity. Development 130: 4097-4107.

10. Kidner CA, Martienssen RA (2005) The role of ARGONAUTE1 (AGO1) in meristem formation and identity. Dev Biol 280: 504-517.

11. Phelps-Durr TL, Thomas J, Vahab P, Timmermans MC (2005) Maize rough sheath2 and its Arabidopsis orthologue ASYMMETRIC LEAVES1 interact with HIRA, a predicted histone chaperone, to maintain knox gene silencing and determinacy during organogenesis. Plant Cell 17: 2886-2898.

12. Uchida N, Townsley B, Chung KH, Sinha N (2007) Regulation of SHOOT MERISTEMLESS genes via an upstream-conserved noncoding sequence coordinates leaf development. Proc Natl Acad Sci U S A 104: 15953-15958.

13. Chao W, Anderson J (2004) Euphorbia esula. In:Crop Protection Compendium CAB International, Wallingford.

14. Schulzschaeffer J, Gerhardt S (1987) Cytotaxonomic Analysis of the Euphorbia Spp (Leafy Spurge) Complex. Biol Zent BI 106: 429-438.

15. Chao WS, Horvath DP, Anderson JV, Foley ME (2005) Potential model weeds to study genomics, ecology, and physiology in the 21 st century. Weed Science 53: 929-937.

16. Raju MVS (1975) EXPERIMENTAL STUDIES ON LEAFY SPURGE
(EUPHORBIAESULAL) 1. ONTOGENY AND DISTRIBUTION OF BUDS AND SHOOTS ON HYPOCOTYL. Bot Gaz 136: 254-261.

17. Lang GA, Early JD, Martin GC, Darnell RL (1987) Endodormancy, Paradormancy, and Ecodormancy - Physiological Terminology and Classification for Dormancy Research. HortScience 22: 371-377.

18. Anderson JV, Gesch RW, Jia Y, Chao WS, Horvath DP (2005) Seasonal shifts in dormancy status, carbohydrate metabolism, and related gene expression in crown buds of leafy spurge. Plant Cell Environ 28: 1567-1578.

19. Horvath DP, Chao WS, Anderson JV (2002) Molecular analysis of signals controlling dormancy and growth in underground adventitious buds of leafy spurge. Plant Physiol 128: 1439-1446.

20. Chao WS, Serpe MD, Anderson JV, Gesch RW, Horvath DP (2006) Sugars hormones, and environment affect the dormancy status in underground adventitious buds of leafy spurge (Euphorbia esula). Weed Science 54: 59-68.

21. Varanasi V, Slotta T, Horvath D (2008) Cloning and characterization of a critica meristem developmental gene (EeSTM) from leafy spurge (Euphorbia esula) Weed Science 56: 490-495.

22. Chang S, Puryear J, Cairney J (1993) A simple and efficient method for isolating RNA from pine trees. Plant Mol Biol Rep 11: 113-116.

23. Clough SJ, Bent AF (1998) Floral dip: a simplified method for Agrobacterium mediated transformation of Arabidopsis thaliana. Plant J 16: 735-743.

24. Zourelidou M, de Torres-Zabala M, Smith C, Bevan MW (2002) STOREKEEPER defines a new class of plant-specific DNA-binding proteins and is a putative regulator of patatin expression. Plant J 30: 489-497.

25. Klimesova J, Martinkova J (2004) Intermediate growth forms as a model for the study of plant clonality functioning: an example with root sprouters. Evolutionary Ecology 18: 669-681.

26. Horvath DP, Anderson JV, Jia Y, Chao WS (2005) Cloning, characterization, and expression of growth regulator CYCLIN D3-2 in leafy spurge (Euphorbia esula). Weed Science 53: 431-437.

27. Jasinski S, Piazza P, Craft J, Hay A, Woolley L, et al. (2005) KNOX action in Arabidopsis is mediated by coordinate regulation of cytokinin and gibberellin activities. Curr Biol 15: 1560-1565.

28. Rupp HM, Frank M, Werner T, Strnad M, Schmulling T (1999) Increased steady state mRNA levels of the STM and KNAT1 homeobox genes in cytokinin overproducing Arabidopsis thaliana indicate a role for cytokinins in the shoot apical meristem. Plant J 18: 557-563.

29. Reymond P, Farmer EE (1998) Jasmonate and salicylate as global signals fo defense gene expression. Curr Opin Plant Biol 1: 404-411.

30. Ananieva K, Malbeck J, Kaminek M, Van Staden J (2004) Methyl jasmonate down-regulates endogenous cytokinin levels in cotyledons of Cucurbita pepo (zucchini) seedlings. Physiol Plant 122: 496-503. 